\title{
Formative Assessment Enriches Learning: Perspectives Of Female University Teachers In Karachi (Pakistan)
}

\author{
Noor Mohammad \\ Faculty of Education \\ Lasbela University \\ Rubina Masum \\ Faculty of Education \\ Iqra University \\ Sheeba Farhan \\ Transformation Integrated Learning System TIS, Karachi
}

\begin{abstract}
This article is drawn from $\mathrm{PhD}$ dissertation and the prime purpose of this research is to study the perspective of female university teachers regarding impact of formative assessment on learning at university level in Karachi (Pakistan) and to suggest the appropriate practices of formative assessment to enhance the learning. The scope of the study is limited to female faculty members of education in the universities in Karachi. The survey design, research strategy, was adopted for the study. The target population, for the study, was 136 female faculty members of education in the universities (public and private) in Karachi (Pakistan). Simple Random Sampling (SRS) design was adopted to select the universities as a unit of sampling and female faculty members of the same universities were the sample size. In this process 66 Female faculty members were selected as sample size from different eight (8) universities. The questionnaire was adopted as research instrument. Data was analyzed and it was found that the formative assessment enriches learning. In the light of findings concrete recommendations were made.
\end{abstract}

Keywords: Formative Assessment, Learning, Female University Teachers.

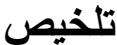

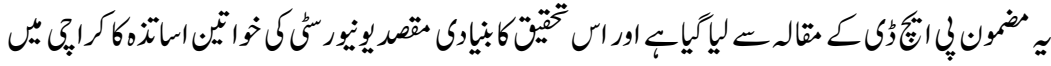

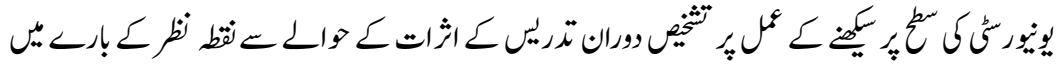

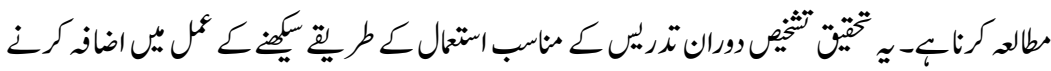

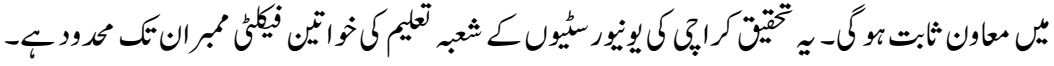

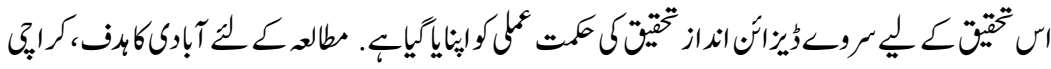

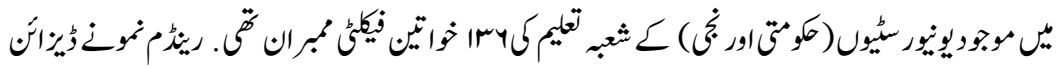




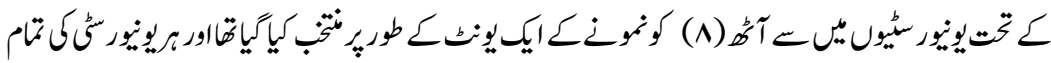

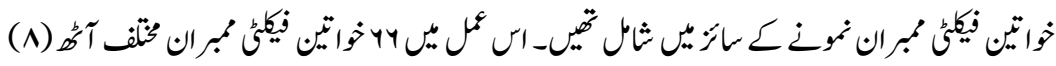

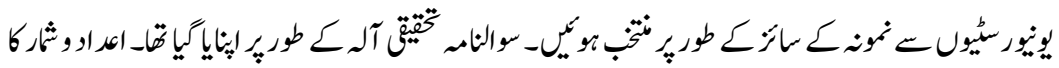

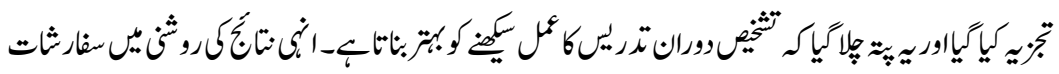

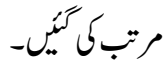

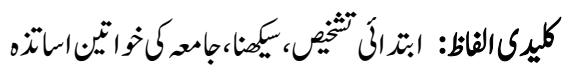

\section{Introduction}

Assessment is one of the key strategies that, if used correctly, can effectively enhance students' learning. Formative assessment is ongoing process which deals with teaching and/or learning during the process of instruction and with the purpose of improving teaching and/or learning. Formative assessment is used for immediate adjustments and improvements in new learning.

The impact of educational assessment, on the lives of the people, is highly significant, because it is used for the certification, selection, diagnosis or placement. At the same time the assessment tools (exams, tests, quizzes, assignments, projects and portfolios) reflect the learning outcomes and teaching effectiveness as well. Teacher assesses informally (Formative Assessment) during evaluation of his/her own teaching and it works as catalyst for support the learners to learn. The formal assessment (Summative Assessment) at the end of course/program may use for career prospects (Iasonas Lamprianou and James A. Athanasou, 2009).

Generally in Pakistan, students of primary to higher secondary (XII), some extend Masters Level, ranked pass or fail on the basis of annual/final examination only. No student is being observed, evaluated, assessed in terms of his/her academic performance, behavior and aptitude throughout the academic session/year. The result of annual examination, in the context of Pakistan, depends upon the students' memory and how much unfair means availed. Resultantly the high ratio of failure students not only leads huge dropout but also develops the long life feelings of frustration, inferiority, among affectless. Hence in this way we are not only wasting the masses but also divert the masses into demoralized, disappointed and psychological handicapped personalities.

As a country, it is required that there must be National Standardized Examination System (Summative Assessment) to ensure the valid and reliable judgments to know either the learners meet national standards/objectives or not and what 
extend they achieved, for placement, grading, ranking and/or certification. But it is also fact that still we are fail to address the issues related to validity, reliability, credibility and improve the quality of education through examination. No one can deny that current examination system needs drastic reforms, in terms of improving the quality of examination papers that could assess the high order thinking (ANTRIEP, Vol. 8, No.1, January - June, 2003).

Since last decade, the importance of formative assessment has been received considerable attention in academically developed countries and the concept of 'Balanced Assessment System' has been introduced which includes formative, interm and summative assessments to balance the assessment in terms of its purpose (Darling Hammond and Pecheone, 2010; Stiggins, 2006, 2008).

The 'Comprehensive Assessment System' supports quality learning. This assessment system comprises formative assessment as well as summative assessment to serve the multi purposes of the assessment at different level of educational venture (Darling Hammond, 2010).

At higher education, there are four functions of the assessment that directly have an impact on students' learning: to motivate for learning, to focus on learning, consolidating and structuring learning, and guiding and modifying learning (Crooks, 1988).

The relation of assessment and learning is acknowledgeable and highly significant because it meets the needs of students, teachers, institutions, and communities in order to indicate the learning progress and the effectiveness of teaching in order to achieve the learning goals (Nightingale et al., 1996).

\section{Purpose of the Study}

The prime purpose of the research was to study the impact of formative assessment on teaching and learning at university level in Sindh. The study would specifically focus on;

- This study will explore the relationship between formative assessment and learning.

- To find out the impact of formative assessment on learning

- Authorities concerned may be guided to streamline the process of assessment

- Realization of female faculty members regarding the importance of formative assessment in the process of teaching and learning 


\section{Literature Review}

Assessment and learning are correlated and both regulate each other. Generally there are three believes that links the assessment with learning. First, assessment influences the learning when it taking place. It means, assessment raises the questions and the responses of the same generate thoughts (product). Second, this process of learning and assessment results the advancement and innovation in the society. Third, standardized assessment tools gauge the achievements of the students in accordance their grades and age so that on school, district, state and national level decisions may be improved (Stiggins, 2002).

Knowledge and understanding of learners based on their prior own knowledge and believes. It suggests that the teacher should consider the prior knowledge and believes of learners and construct new knowledge and understanding on those grounds. Teacher also has to complete and correct the knowledge and perceptions of learners through open discussion and open end questions. Assessment process should compare the prior and new learning of learners which resulted during instruction. Assessment should depict the thinking process of students and their teachers. Proper formative assessment modifies and refines the thinking process of students throughout the process of teaching/learning (Bransford et al, 2000).

Effective learning takes place when the student actively involved in the process of learning and he/she has to regulate his/her own learning. In other words the active engagement of students leads to effective and productive learning. Teaching strategies should be compatible with learning theories. Assessment should be integrated with the instruction and learning. Activities and tasks of assessment should be designed in a way where students get involved in the process of teaching and learning. Assessment should in the form of peer-assessment, selfassessment and feedback on the spot so that students could adjust their learning as desired.

The new approach of learning leads to rethinking of process to teaching and assessment. The constructivist and socio-cultural school of thoughts encourage assessment culture as a part of teaching and learning. Assessment should focus on process of learning besides of its outcomes. The educators know the role of assessment that consistent with learning process and products (Birenbaum, 2003).

Formative assessment is commonly conducted during a course or assignment. It is called "educated assessment", it helps to learn. This may be a teacher or a learner's opinion about students work and generally it is not used for grading. Formative assessment can be carried out though diagnostic and standardized tests, quizzes, viva voce and assignment/project. It aims to clear the status of students' learning throughout the course. 
The said assessment culture promotes learning similarly as formative assessment does. As per research of Black and William (1998 and 1999) and OECD/CERI (2005), formative assessment boosts the learning achievements of students. The ratio of achievement is likely more in lower achieving students. In this assessment culture with the association of current learning theories, the performance of students and teacher is enhanced in the process of learning and assessment.

According to Black and William (1998), teachers should have full command and deep understanding of formative assessment so that they could assist the students to set the criteria for assessment and overcome the gaps between present learning achievements and desired learning goals.

Research suggests that formative assessment ensures the enthusiastic involvement of teacher and learners in the process of learning; it is also revealed that formative assessment improves the quality in students' work and their commitment to learn. It improves the quality and learning achievements of students and satisfaction level of teachers too (Hayward and Hedge, 2005).

According to Popham (2008) formative assessment is planned process rather than accidental. Formative assessment looks like an integrated part of teaching and learning activities where assessment tools are incorporated. The use of different strategies and tools by the teacher to know the current level of students' understanding and identify the gaps and adjust the teaching to achieve the planned learning outcomes, is called formative assessment (Heritage, 2007).

Formative assessment improves and accelerates the learning process (Sadler, 1998, William and Leahy, 2007). Formative assessment used for immediate adjustments for new learning (Shepard, 2008). This assessment regulates the teaching and learning in accordance to meet the set outcomes of the lesson (FAST SCASS, 2006).

When the act of teaching and learning is going on the formative assessment adjusts the ongoing process of teaching and learning for effective learning. It improves the learning achievements of students (Heritage, 2011 and CCSSO, 2008).

Formative assessment is not a product or event or one time measurement but it is a minute by minute and day by day activity (Leahy, et al., 2005). It is an intended practice that enables the teacher and students to know the level of learning after teaching. It also helps the teacher to modify his/her teaching (Heritage, 2010 and Clark, 2011). 
Review of hundreds research articles it is revealed that students' learning performance enhances by effective use of formative assessment and the same works as a motivating factor for students towards their studies, as well (Hattie \& Timperley, 2007; Marshall, \& Wiliam, 2002 and Black \& Wiliam, 1998).

According to concluding remarks of Black \& William (1998a), Geisler-Brenstein \& Schmeck (1996), Vispoel and Austin (1995) and Schunk \& Swartz (1993), the formative assessment bridges up the gaps students' current status, in terms of learning, and targeted learning. Formative assessment emphasises on the learning outcomes of the students and it also encourages students towards self-regulated learning that is why the confidence level of students boosts up.

As per findings of research reviews done by Crooks (1998) and Natriello (1987), the formative assessment has a significantly positive impact of the attitudes and achievements of the students.

Most research studies in field of assessment proved that the formative assessment is very effective tool for teacher to improve his/her teaching strategies accordingly (Young \& Kim, 2010; OECD, 2008; Chappius \& Chappius, 2007; Staginess, 2005; Black \& William, 2004; Stiggins, 2002 and Black \& William, 1998).

According to Hattie \& Timberly (2007) and NRC (2004) number of research studies revealed that timely and targeted feedback on students' work, improves the learning and enhance the understanding of the students. As per reports of National Science Research Council (1996), assessment and instruction are two sides of the same coin; the process of learning is going on side by side when assessment is.

Dunn and Mulvenon (2009) differ that the formative assessment significantly improves the academic achievements. They argue that the poor evidences are in the support of the statement.

Number of studies investigated and proved that different techniques of formative assessment have the learning benefits in academia and further concluded that these techniques support the teacher to bridge up the students' achievement gaps (William, 2006).

According to Madison-Haris, Mouneke and Times (2012), Gallagher and Worth (2008), formative assessment helps the teacher towards targeted instruction that might achieve the learning goals, it supports students' learning and it get known the current learning achievements.

Research confirmed that formative assessment practices raise the test scores of the students and it also confirmed the significant improvement in students' 
achievements. Simultaneously teachers, trainers, school heads and educationists emphasis the idea to ensure the effectiveness of formative assessment in classroom in order to achieve optimum learning outcomes Black, et al. (2003).

\section{Research Design}

The survey research design was adopted to collect the data through research instrument (Questionnaire). The survey is most commonly used in educational research. This design of research deals to measure the attitude, opinions and achievement in the natural settings. There are two types of survey research; longitudinal and cross sectional. In this study the survey research with cross sectional design was used. The Simple Random Sampling (SRS) design was adopted for sampling. The research instruments questionnaire and interview protocol was administered through personal survey. The critical analysis and evaluation of related literature was a part of this study.

The female faculty members (136) of education, universities (public and private) in the Karachi (Pakistan) was the target population for this study, and 66 faculty members were selected as sample from eight (8) different universities.

\section{Results and Findings}

Chi square $\left(x^{2}\right)$ was applied to analyze the Null Hypothesis $\left(\mathrm{H}_{\mathrm{o}}\right)$, 'There is no significant impact of formative assessment on learning according to female university teachers in Karachi (Pakistan)'.

\section{Table: 1}

Application of $\boldsymbol{x}^{2}$ to test the Null Hypothesis $\left(\mathrm{H}_{0}\right)$

\begin{tabular}{|c|c|c|c|c|c|}
\hline Steps & Frequency & $\begin{array}{c}\text { Strongly } \\
\text { Favourable }\end{array}$ & $\begin{array}{c}\text { Mildly } \\
\text { Favourable }\end{array}$ & $\begin{array}{c}\text { Un } \\
\text { Favourable }\end{array}$ & Total \\
\hline Step 1 & Fo & 773 & 1150 & 387 & 2310 \\
\hline Step 2 & $\mathrm{Fe}$ & 770 & 770 & 770 & 2310 \\
\hline Step 3 & fo $-f e$ & 3 & 380 & -383 & \\
\hline Step 4 & $(f o-f e)^{2}$ & 9 & 144400 & 146689 & \\
\hline Step 5 & $\frac{(f o-f e)^{2}}{f e}$ & 0.01 & 187.53 & 190.51 & - \\
\hline Step 6 & $x^{2}=\sum \frac{(\mathrm{fo}-\mathrm{fe})^{2}}{\mathrm{fe}}$ & 0.01 & 187.53 & 190.51 & 378.05 \\
\hline Step 7 & \multicolumn{3}{|c|}{ Find the degree of freedom $(\mathrm{df})$} & & \\
\hline & \multicolumn{3}{|l|}{$\mathrm{df}=\mathrm{K}-1=3-1=2$} & & \\
\hline Step 8 & Conclusion & & & & \\
\hline
\end{tabular}

The computed value of $x^{2}$ (378.05) is greater than the tabulated value of $x^{2}(5.99)$, so it is concluded that the formative assessment enriches learning according to 
female university teachers in Karachi (Pakistan) and the Null Hypothesis $\left(\mathrm{H}_{\mathrm{o}}\right)$ is rejected.

Further treatment of the data revealed that most Female faculty members believe that formative assessment has positive impact on teaching and learning at university level.

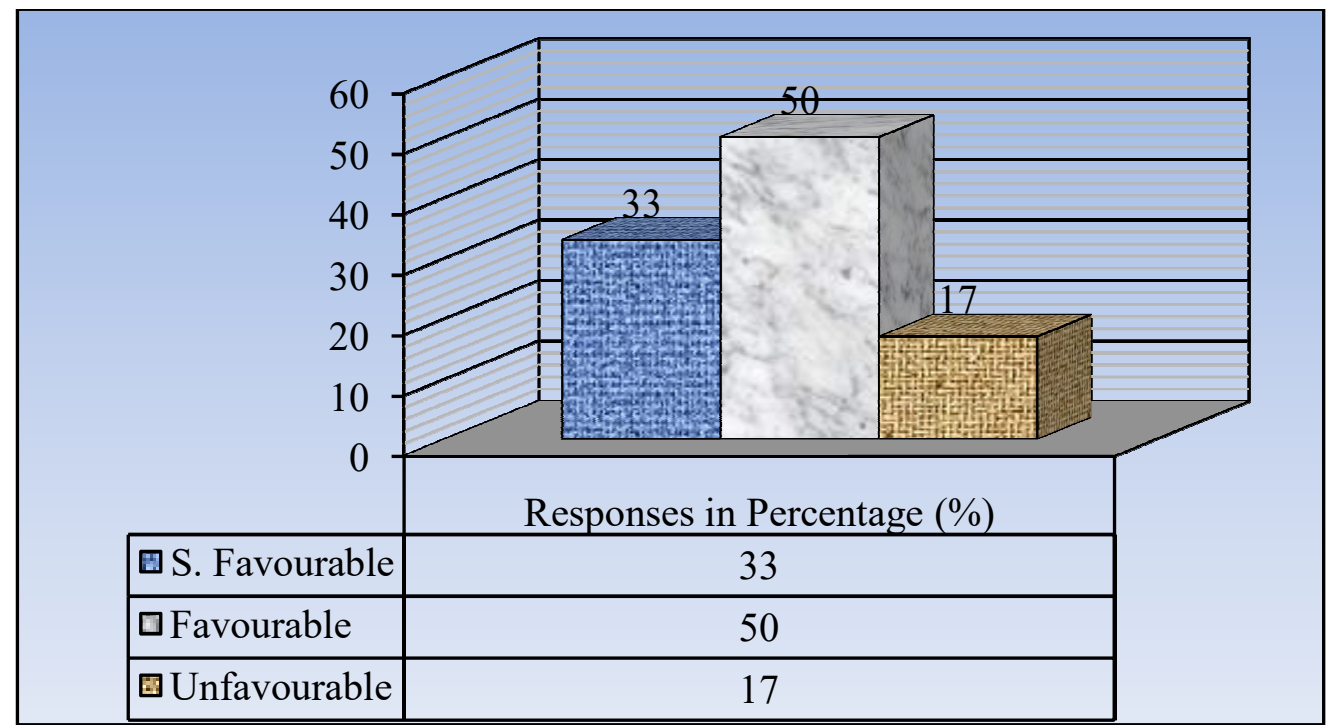

Figure 1: Formative Assessment enriches learning

$33 \%$ respondents strongly agreed and 50\% agreed with the statement that 'formative assessment has a significant impact on teaching and learning at university level in Sindh (Pakistan)' while 17\% respondents were not in favour with the statement.

\section{Conclusions}

The following conclusions are drawn from the findings of this study;

It is concluded that Formative Assessment enriches learning at university level, in other words, Formative Assessment supports the process of teaching and learning.

The result of research also revealed that Formative Assessment enables the teacher to realize the deficiencies in his/her teaching and it also helps the teacher to modify his/her teaching strategies accordingly, so that the teaching efficiency may be ensured. 
It is also concluded that formative assessment develops the interest and motivation among the students towards their studies in order to improve their learning performance.

\section{Recommendations}

On the basis of findings of the study the following recommendations have been made for the improvement in the field of formative assessment in order to improve the quality in education:

- Capacity building programs may be arranged for teachers to familiarize them with formative assessment, its importance and process and urge them for proper implementation in the context of teaching and learning.

- Management of educational institutions supposed to ensure proper implementation of formative assessment in educational/classroom setup.

- The formative assessment may be incorporated in the National Education Policy and the National Curriculum accordingly.

- Frequent and effective use of formative assessment should be ensured at classroom level.

- The policy and effective tools for the implementation of formative assessment may be designed.

- 'Assessment Literacy' may be taught at all institutes of teacher education as a part of syllabus.

- The impact of formative assessment should be on grading of the students and the worth of formative assessment reports should be around $50 \%$ of the total marks.

- An action/implementation plan of formative assessment for teacher may be developed at subject/classroom level.

- Effective techniques and reliable and valid tools of formative assessment may be introduced with the help of experts of the field.

\section{References}

Asian Network of Training and Research Institutions in Educational Planning (ANTRIEP), vol.8:1, January - June, 2003).

Bhatti, M. A. (1987), Secondary Education in Pakistan: Perspective Planning, Islamabad: National Education Council.

Black, P. \& Wiliam, D. (1998a), Assessment and Classroom Learning: Assessment in Education. vol.5, pp.7-73.

Black, P. \& Wiliam, D. (1998b), Inside the Black Box: Raising Standards through Classroom Assessment. King's College, London. 
Black, P., \& Wiliam, D. (2004). The Formative Purpose: Assessment Must First Promote Learning. In M. Wilson (Ed.), Towards Coherence between Classroom Assessment and Accountability, Chicago: University of Chicago Press.

Black, P.; Harrison, C.; Lee, C.; Marshall, B. \& Wiliam, D. (2002). Working Inside the Black Box, London, UK: King's College London Department of Education and Professional Studies.

Council of Chief State School Officers (CCSO), (2008). Attributes of Effective Formative Assessment, Washington, DC: Author.

Creswell, J. W. \& Plano Clark, V. L. (2011). Designing and Conducting Mixed Methods Research (2nd ed.). Thousand Oaks, CA: Sage.

Crooks, T.J. (1988). The Impact of Classroom Evaluation Practices on Students. Review of Educational Research, vol.58, pp.438-481.

Gallagher, C. W. (2008). Kairos and Informative Assessment: Rethinking the Formative/Summative Distinction in Nebraska. Theory into Practice, vol.48, pp.81-88.

Geisler-Brenstein, E. \& Schmeck, R. (1996). The Revised Inventory of Learning Processes: A Multifaceted Perspective on Individual Differences in Learning. In M. Birenbaum and F. Dochy (Eds) Alternative in Assessment of Achievement, Learning Processes and Prior Knowledge: Evaluation in Education and Human Service (pp.283-317) New York: Kluwer Academic.

Harlen, W. \& James, M. (1996). Creating a Positive Impact of Assessment on Learning. Paper Presented at the Annual Meeting of the American Educational Research Association, New York.

Hattie, J. \& Temperley H. (2007). The Power of Feedback. Review of Educational Research, vol.77:1, pp.81-112.

Heritage, M. (2010), Formative Assessment and Next-Generation Assessment Systems: Are We Losing an Opportunity? Washington, DC: Council of Chief State School Officers.

Kyong-Youm Kim, (2010). Keypad Backlighting Device, Patent Issued No. US $2006 / 7834854$. 
Leahy, S., Lyon, C., Thompson, M. \& Wiliam, D. (2005), Classroom Assessment: Minute-by-Minute and Day-by-Day. Educational Leadership, vol.63:3, pp.18-24.

Madison-Harris, R., Muoneke, A. \& Times, C. (2012). Using Formative Assessment to Improve Student Achievement in the Core Content Areas. Southeast Comprehensive Center"s (SCC) Briefing paper. 4700 Mueller Blvd: SSC at SEDL

Mirza, M. (1999). Examination System and Teaching and Practice of Teachers at Secondary, Higher Secondary and O' Level, Bulletin of Education and Research, No. 1, Lahore: Institute of Education and Research Quaid -EAzam Campus, University of the Punjab.

Natriello, G. (1987). The Impact of Evaluation Processes on students, Educational Psychologist, vol.22, pp.155-175.

Nightingale et al., (1996). Assessing Learning in Universities, Sydney: UNSW Press.

Ramprasad, A. (1983). 'On the Definition of Feedback'. Behavioural Science, vol.28, pp.4-13.

Sadler, D. R. (1998). Formative Assessment: Revisiting the Territory. [Electronic version] Assessment in Education, vol.5:1, pp.77-84, Sanchez and Ice, 2005).

Schunk, D. H. \& Swartz, C. W. (1993). Goals and Progressive Feedback: Effects on Self-Efficacy and Writing Achievement. Contemporary Educational Psychology, vol.18, pp.337-354.

Stiggins, R.J. (2009). Assessment Manifesto: A Call for the Development of Balanced Assessment Systems. Portland, OR: ETS Assessment Training Institute.

Vispoel, W.P. \& J.R. Austin (1995). Success and Failure in Junior High School: A Critical Incident Approach to Understanding Students' Attributional Beliefs, American Educational Research Journal, vol.33, pp.377-412.

Wiliam D. (2006). Formative Assessment: Getting the Focus Right, Educational Assessment, vol.11:3\&4, pp.283-289. 
Noor Mohammad is Ph.D Scholar, Hamdard University Karachi \& Assistant Professor Faculty of Education, Lasbela University

Dr. Rubina Masum is an Assistant Professor, Faculty of Education, Iqra University, Karachi.

Dr. Sheeba Farhan is Project Head, Transformation Integrated Learning System, Karachi. 